\title{
Dupuytren's Diathesis in an African Male
}

\author{
Richard Mbuva ${ }^{1}$, James Kigera², Michael Maru³, Tom Mogire², Ezekiel Oburu²
}

1. Defence Forces Hospital, Nairobi

2. School of Medicine, University of Nairobi

3. PCEA Kikuyu Hospital

Correspondence to: Dr. Richard Mbuva, P. O. Box 19676-00200, Nairobi, Kenya. Email: mbuvarichard@gmail.com

\section{Summary}

Dupuytren's disease is not common in the African population. Like in other populations early intervention before severe contractures is important in order to prevent recurrence. We present a case of a young African with Dupuytren's diathesis.

\section{Introduction}

Dupuytren's diathesis is a severe form of Dupuytren's disease that presents with palmar contractures at a young age and is usually bilateral and may involve ectopic sites including, plantar aspect of the foot (Ledderhose disease) and penis (Peyronies disease) (1). Although the rate of Dupuytrens reported in the Caucasian populations is five times higher than in Africans, bilateral disease in blacks is even more rare (2). There are a few case reports of the disease documented in the African population (3). Dupuytrens has been associated with alcohol, smoking, diabetes, epilepsy, trauma and genetic factors (autosomal dominant with variable penetrance) among others (4-7). The management of the disease is primarily surgical although other modes of management are used. This is a case of Dupuytren's diathesis in an African patient and review the literature to highlight this rare condition.

\section{Case report}

A 42 year old right handed male presented to the orthopedic unit of a local mission hospital after he noticed progressive deformity with difficulty in using his right hand over a period of six months without any history of trauma. The problem initially started as a painful palmar nodule with later progression to a flexion deformity of the 4 th and 5 th digits. He was unable to perform basic tasks like washing his face. Two years prior he had presented with a similar deformity in the left hand that was corrected surgically. He is a social drinker with no history of alcoholism. There was
Keywords: Dupuytren's, Diathesis, African, Surgery

Ann Afr Surg. 2016;13(2): 84-5.

DOI: http://dx.doi.org/10.4314/aas.v13i2.12

no history of diabetes or epilepsy nor family history of a similar condition.

Physical examination revealed bilateral hand involvement. On the right hand, the small finger had an $80^{\circ}$ flexion contracture at the proximal interphalangeal (PIP) joint and the ring finger had a $55^{\circ}$ contracture at the PIP. The left hand had a healed scar on the palmar aspect with a flexion contracture of the middle finger of about $20^{\circ}$ at the metacarpal phalangeal joint. On further examination the patient was found to have involvement of the feet and the penis. The patient underwent partial fasciectomy of his deformities. Full correction was achieved intra-operatively ( Figure 2). Post operatively a splint was applied.

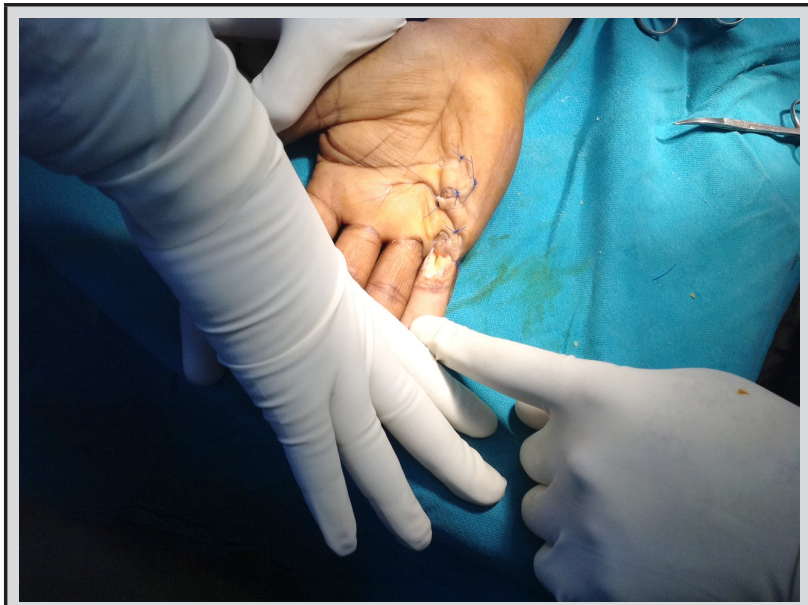

Figure 1: Post Operative Correction of the Deformity 


\section{Discussion}

Dupuytrens diathesis is a relatively uncommon disease in persons of African descent. In an epidemiologic study by McFarlane there were only 5 Africans with dupuytren's disease out of the 1150 surgical patients (8). Muguti in 1993 had a series of 4 indigenous Zimbabweans of whom 3 were male and 1 female. The males had history of trauma and the female had history of epilepsy. None had a family history of dupuytren's (9).

Richard-Kaido et al reported 3 cases of dupuytren's in West Africans and argued that the disease may be more common than previously thought. While this may be true and some cases may go unnoticed, dupuytren's involving Africans is sparsely reported in the literature as compared to other populations (10). The largest series of Africans with bilateral hand involvement was presented by Mitra and Goldeinstein. They followed up 8 patients of which 5 had bilateral hand involvement (11). Mennen reported 6 African patients with Dupuytren's contracture (12). This established Dupuytren's Disease in Africans through genotyping. Thirteen sporadic cases were identified by Furnas in East Africa in 1979 and by Mennen $(13,14)$. Our case, unlike other cases reported in Africans, involves a patient with Dupuytren's diathesis. As noted from literature, Dupuytren's remains relatively uncommon in our set up. However, doctors in the region should be aware of the disease as this will enable us to report other cases of Dupuytren's and pick the occasional diathesis as in our case.

\section{References}

1. HindochaS, StanleyJK, Watson S, etal. Dupuytren's Diathesis Revisited: Evaluation of Prognostic Indicators for Risk of Disease Recurrence. J Hand Surg Am. 2006;31(10):1626-34.

2. Saboeiro AP, Porkorny JJ, Shehadi SI, et al. Racial Distribution of Dupuytren's disease in
Department of Veterans Affairs Patients. Plast Reconstr Surg. 2000;106:71-5.

3. Geoghegan JM, Forbes J, Clark DI, et al. Dupuytren's Disease Risk Factors. J Hand Surg Br. 2004;29:423-6.

4. Arkkila PE, Kantola IM, Viikari JS. Dupuytren's Disease: Association with Chronic Diabetic Complications. J Rheumatol. 1997;24:153-9.

5. Burge P, Hoy G, Regan P, et al. Smoking, Alcohol and the Risk Of Dupuytren's Contracture. J Bone Joint Surg Br. 1997;79:206-10.

6. Critchley EM, Vakil SD, Hayward HW, et al. Dupuytren's Disease in Epilepsy: Result of Prolonged Administration of Anticonvulsants. J Neurol Neurosurg Psychiatry. 1976;39:498-503.

7. Chansky HA, Trumble TE, Conrad EU 3rd, et al. Evidence for a Polyclonal Etiology of Palmar Fibromatosis. J Hand Surg Am. 1999;24:339-44.

8. McFarlane RM. Epidemiology of Surgical Patients. In: McFarlane RM, McGrouther DA, Flint MH, eds. Dupuytren's disease. London: Churchill Livingstone, 1990: 201-38.

9. Muguti G, Appelt B. Dupuytren's Contracture in Black Zimbabweans. Centr Afr J Med 1993;39:129-32.

10. Richard-Kadio M, Guedegbe F, Dick R, et al. Dupuytren's Contracture: Review of the Literature. Case Report of a Black African. Med Trop 1990;50:311-13.

11. Mitra A, Goldstein RY. Dupuytren's Contracture in the Black Population: A Review. Ann Plast Surg. 1994;32: 619-22.

12. Mennen U. Dupuytren's Contracture in the Negro. J Hand Surg 1986;11A:61-64.

13. Furnas DW. Dupuytren's Contracture In A Black Patient In East Africa (Letter). Plast Reconstr Surg. 1979;64:250-1.

14. Mennen U, Grabe RR. Dupuytren's Contracture in a Negro: A Case Report. J Hand Surg 1979;4:451-3. 